\title{
Effect of Precipitation Hardening on Hardness and Microstructure of Austenitic Manganese Steel
}

\author{
S. Aribo, K.K. Alaneme, D.O. Folorunso and F.O. Aramide \\ Department of Metallurgical and Materials Engineering, Federal University of Technology. \\ PMB, 704, Akure, Nigeria \\ *Corresponding Author: aribosunny@yahoo.com \\ Phone Number: +2348038161807
}

\begin{abstract}
The effect of precipitation hardening on microstructure and hardness of Austenitic Manganese Steel has been studied. Samples of the steel were machined, autenitized at $1000^{\circ} \mathrm{C}$ and held for one hour, water quenched and then aged at different temperatures and holding times. The samples were artificially aged at $600^{\circ} \mathrm{C}$ and $700^{\circ} \mathrm{C}$ and were held for one, two and three hours. Microstructures and hardness values of the samples were taken. It was found out that sample aged at $700^{\circ} \mathrm{C}$ for 2 hours has its carbide particles finely dispersed on the austenite matrix. This led to an increase in the hardness.
\end{abstract}

Key words: precipitation, hardening, ageing, hardness, microstructure, carbide, austenitized, austenitic manganese steel.

\section{INTRODUCTION}

The wear- resistance of the Austenitic Manganese Steel (AMS) which comes from the work hardening of the steel in service condition by the application of impact loading allows the steel to be used in the condition of high wear [3], but the crushing efficiency of the modern jaw and cone crushers has been raised by increasing the stroke length and by transforming the crushing by compression alone into a combined effect of compression and shear. In these types of crushing processes, the formerly impact load has largely been replaced by an abrasive wear with a result that the impact loads against the wear parts have not been strong enough to cause the maximum work hardening of the steel and the relative service life of the wear parts have shortened [3]. 
The situation is the same in the excavator buckets and loader shovels when loading fine grain materials, where the impact and compression loads are not always sufficient for the work hardening of the steel [3]

Although wear parts produced by forging and hot rolling already have enough hardness to withstand the wear action, but most parts used in the above applications are produced by casting. These castings are strengthened by the solution annealing and quenching and depend mainly on the work hardening of the steel to last long [1].

This has led to various researches on how to strengthen the steel with some proposing the addition of alloying elements to increase its hardness and wear-resistance. Unfortunately this has led to little or no improvement in the hardness of the steel [2].

The above reasons have necessitated further research into the steel to find a means into how the wear resistance can be improved, hence the reason for this research.

The conventionally heat treatments for Austenitic Manganese Steel is Solution Annealing followed by quenching, which is preformed by heating the steel between the temperature range of $1000^{\circ} \mathrm{C}$ to $1100^{\circ} \mathrm{C}$, held for enough time depending on the size of the steel and then cooled rapidly by quenching in water. This gives the Steel a Brinell number between 200 to 250, which is low for effective wear resistance [2].

This research finds an additional form of heat treatment, which can be used to increase the hardness of the steel and thereby increase the wear resistance and in turn the service life.

\section{MATERIALS AND METHODS}

The test material for the experimental research is an Austenitic Manganese Steel with predetermined composition shown in Table 1.

Table 1. Chemical composition of the Austenitic Manganese Steel.

\begin{tabular}{|c|c|c|c|c|c|c|c|}
\hline C \% & Si \% & & P \% & Mn \% & $\mathrm{Ni} \%$ & Cr \% & Мo \% \\
\hline 1.27513 & 0.58395 & 0.01773 & 0.02855 & 13.78427 & 0.02737 & 2.24930 & 0.01153 \\
\hline V\% & $\mathrm{Cu} \%$ & W \% & $\mathrm{Ti} \%$ & Sn $\%$ & Co $\%$ & $\mathrm{Al} \%$ & $\mathrm{Nb} \%$ \\
\hline 0.00386 & 0.05224 & 0.02143 & 0.00892 & 0.00534 & 0.01041 & 0.00323 & 0.00956 \\
\hline
\end{tabular}

\begin{tabular}{ll}
\hline $\mathrm{Mg} \%$ & $\mathrm{Fe} \%$ \\
\hline 0.01689 & 81.8903 \\
\hline
\end{tabular}


The as received Austenitic Manganese Steel was machined to nine pieces of dimension $15 \mathrm{~mm}$ by $15 \mathrm{~mm}$ by $15 \mathrm{~mm}$. The samples were then austenitized at $1000^{\circ} \mathrm{C}$ for thirty minutes before quenching in water. Thereafter the samples were subjected to a second stage heat treatment which involved ageing at two different temperatures of $600^{\circ} \mathrm{C}$ and $700^{\circ} \mathrm{C}$ for holding times ranging between one and three hours before air cooling. Three samples were used as control samples.- two were austenitized at $1000^{\circ} \mathrm{C}$ for thirty minutes and one was air cooled while the other was furnace cooled. The third sample was left in the as - machined condition.

Hardness measurements utilizing the Rockwell Hardness Tester (HRB) and micro structural examination were utilized for characterization of various heat treatment structures produced.

Table 2. Samples Designations.

\begin{tabular}{|l|l|l|l|l|l|l|}
\hline Temperature $\left({ }^{0} \mathrm{C}\right)$ & \multicolumn{3}{|l|}{600} & \multicolumn{3}{l|}{700} \\
\hline sample & A1 & A2 & A3 & B1 & B2 & B3 \\
\hline $\begin{array}{l}\text { Holding } \\
\text { time(HOURS) }\end{array}$ & 1 & 2 & 3 & 1 & 2 & 3 \\
\hline
\end{tabular}

\subsection{RESULTS AND DISCUSSION}

\subsection{Results}

\subsubsection{Micrographs of the Samples}

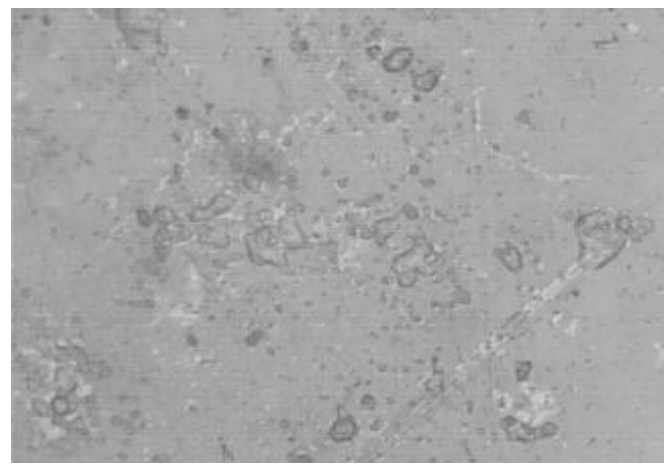

Plate 1. Microstructure of the As-Machine Sample, Etch with $2 \%$ nital, magnification X 400

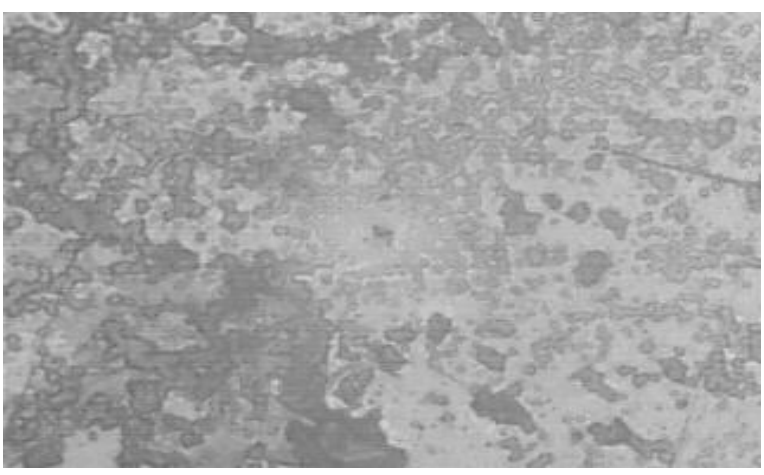

Plate 2. Microstructure of the FurnaceCooled Sample. Etch with $2 \%$ Nital, magnification X400 


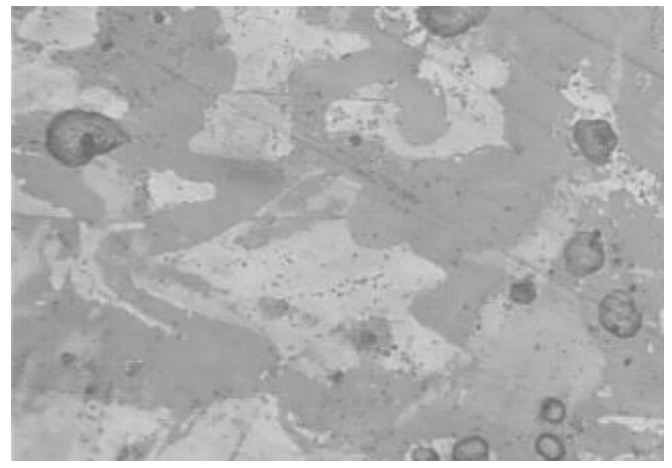

Plates 3. Microstructure of the Normalized Sample, Etch With 2\% Nital, Magnification X400

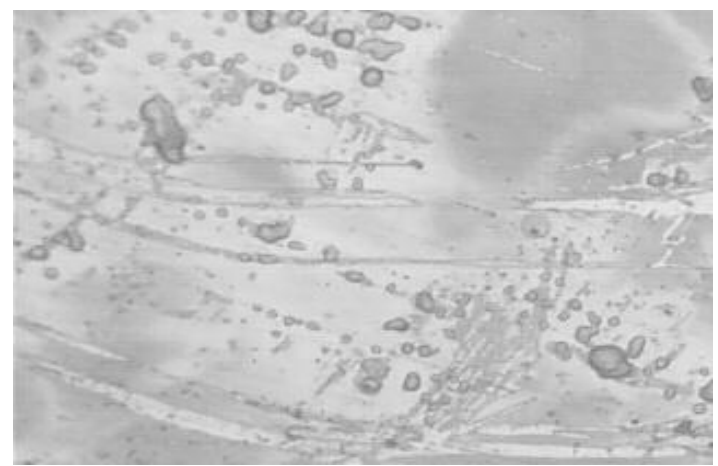

Plates 4. Microstructure of the water quenched Sample. Etch with 2\% Nital, Magnification X400

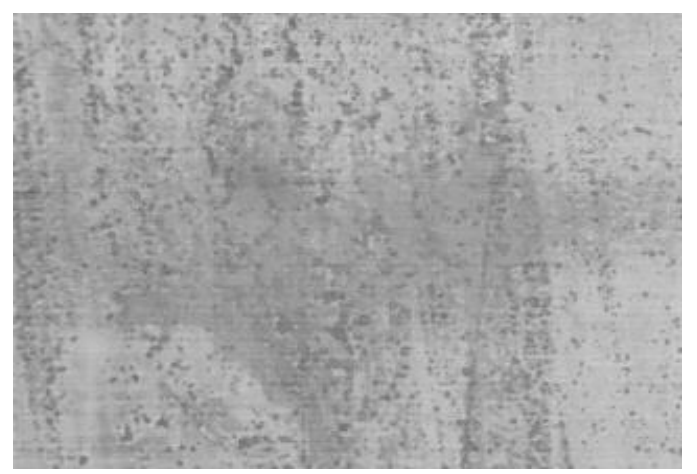

Plates 5. Microstructure of the Sample Heated to $700^{\circ} \mathrm{C}$ and Held for 1 hour, Etch with 2\% Nital, Magnification X400

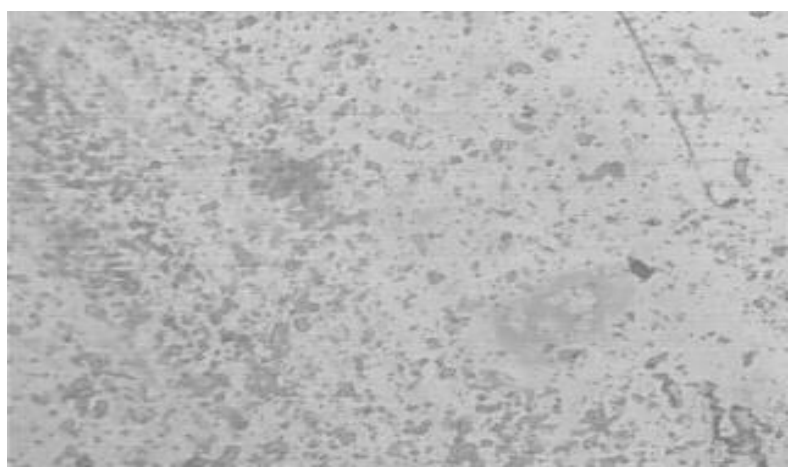

Plates 6. Microstructure of the Sample Heated to $700^{\circ} \mathrm{C}$ and Held for 2 Hours, Etch with 2\% Nital, Magnification X400

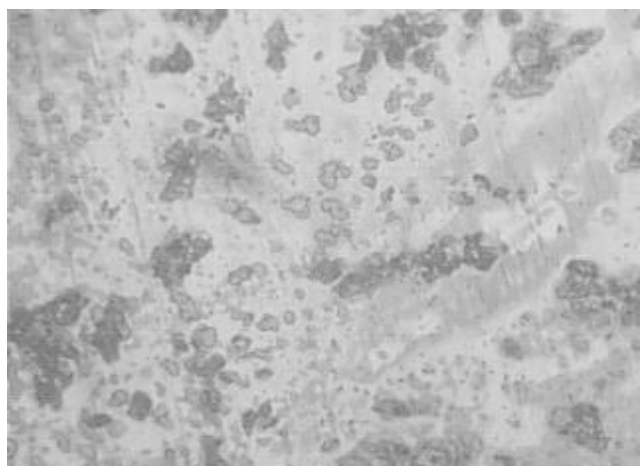

Plates 7. Mhcrostructure of the Sample Heated to $700^{\circ} \mathrm{C}$ and Held for 3 Hours, Etch with 2\% Nital, Lagnification X400

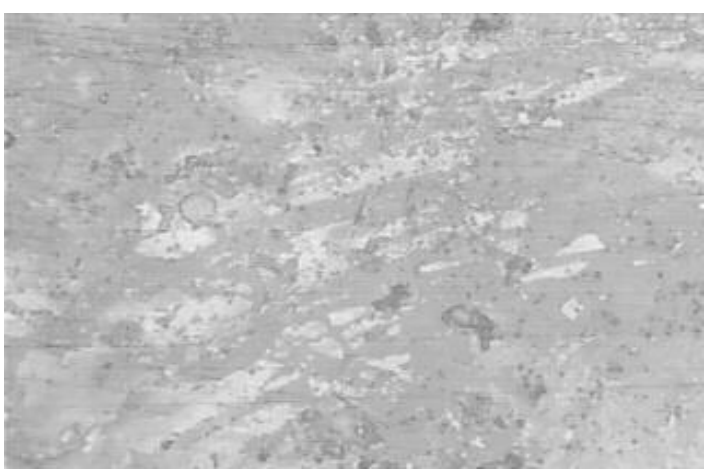

Plates 8. Microstruc4ure of the Sample h\%ateD to $600^{\circ} \mathrm{C}$ and h\%ld for 1 hour. Etch with $2 \%$ nital, magnification X400 


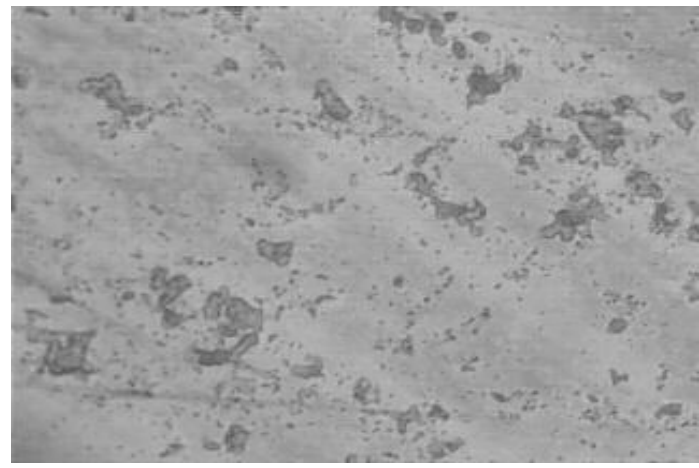

Plates 9. MIcrostructure of the Sample heated to $600^{\circ} \mathrm{C}$ and held for 2 hour. Etch with $2 \%$ nital, magnification X400

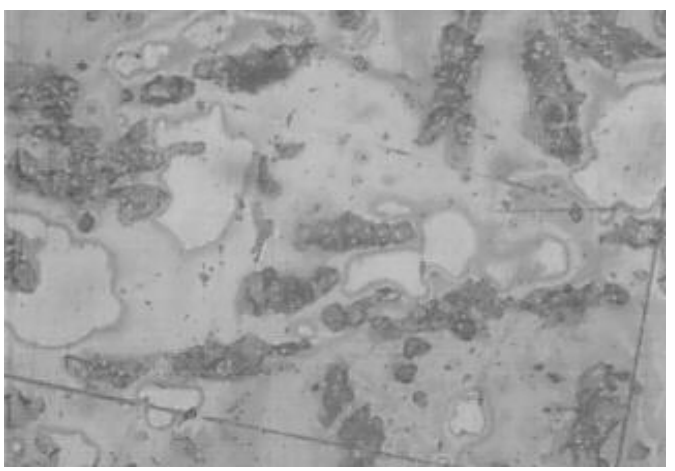

Plates 10. Microstructure of the Sample Heated to $600^{\circ} \mathrm{C}$ and Held for 3 Hours, Etch with 2\% Nital, Magnification X400

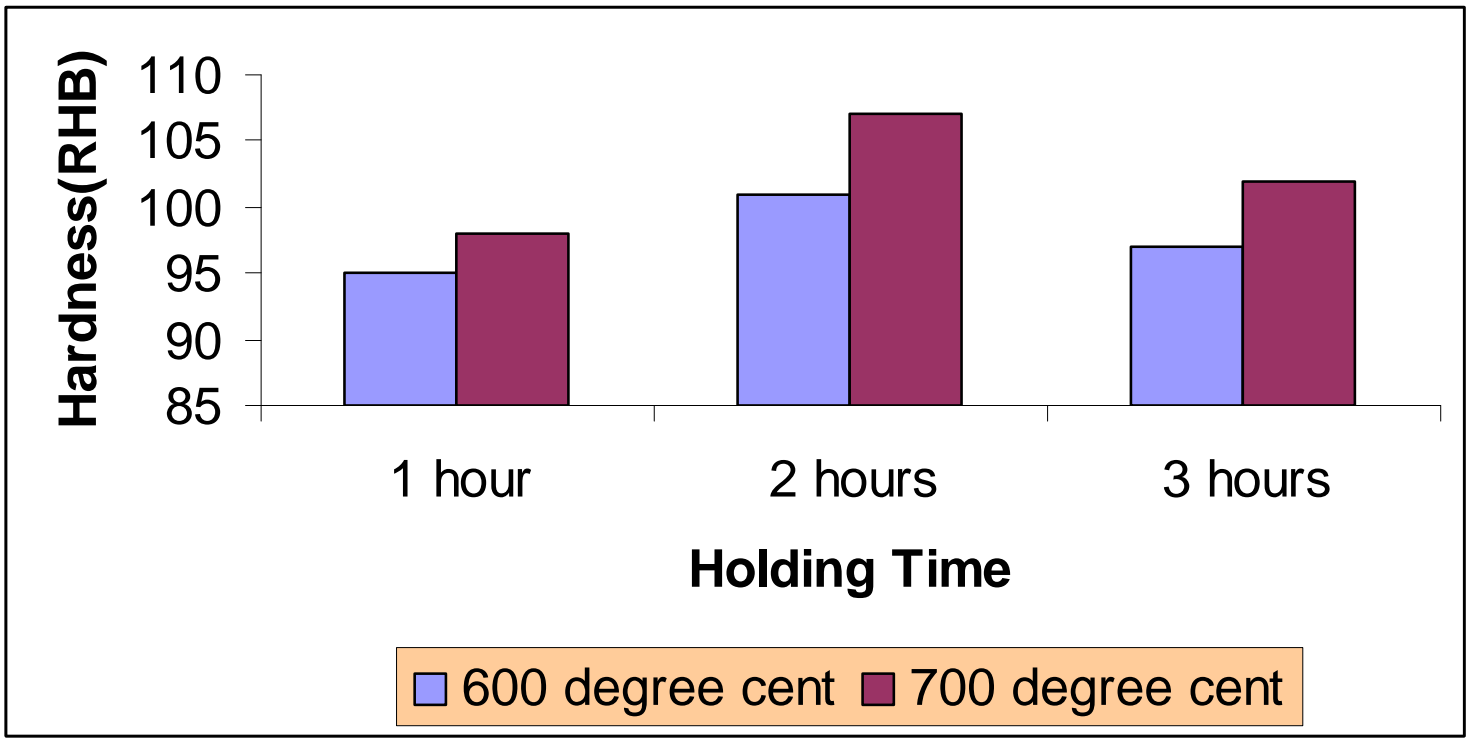

Figure 1. Chart of Variation Hardness with Ageing Time and Temperature.

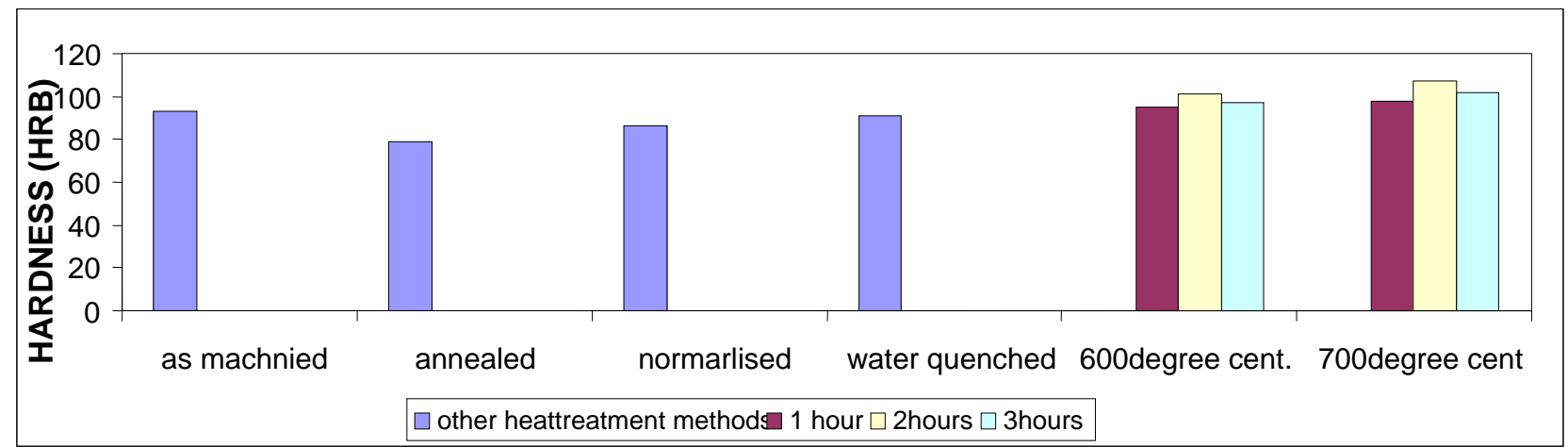

Figure 2. Chart Comparing Values for Aged Samples and those of Other Heat Treatment Methods. 


\section{DISCUSSION}

Comparing the average hardness of the samples as machined, as normalized, annealed and water quenched, it is observed that the sample as machined has the highest hardness but the difference from the water quenched sample is marginal. This confirms the fact that wear abrasion actions on Austenitic Manganese Steel do not increase the hardness considerably as it would be desired for long service life in application for only abrasion without impact action [4].

When the steel was aged at $600^{\circ} \mathrm{C}$ it shows improvement in hardness. The hardness increases as the holding hour increases from the first hour to the second hour but the hardness dropped at the third hour.

Ageing at $700^{\circ} \mathrm{C}$ has a similar result to those mentioned above, but the hardness at the second hour is higher than the one recorded at $600^{\circ} \mathrm{C}$.

Figure 1 gives the summary of all the explanations above. It shows that the best hardness is attained when the steel is aged at $700^{\circ} \mathrm{C}$ for 2 hours

Figure 2 helped to further show that ageing at $700^{\circ} \mathrm{C}$ for 2 hours is the best and will be recommended for ageing of the steel for industrial applications where only wear abrasion action is present and also to improve the hardness of the Steel for other applications.

The Micrographs of these various treatments are shown from Plate 1 to 10 . They helped to throw more light on how different ageing treatments affect the hardness of each of the samples.

The micrograph of the as-machined sample shows inclusion of small sized carbide particles which explain why the Steel show high hardness as compared to the annealed and normalized samples. The micrograph of these other treatments showed that the carbide has formed large carbide network connected through the whole microstructures and this has caused the austenite phase to transform to ferrite bringing about the reduction in hardness.

The microstructure of the annealed samples shows the carbide covering the whole structure. The normalized samples also show the carbide forming a network round the austenite phase in the structure. During annealing there will be enough time for carbide network breakdown explaining why the hardness value for the annealed sample was low compared to the normalized samples.

Microstructures of the $700^{\circ} \mathrm{C}$ treatment show continuous increase in the carbide forming as inclusion in the austenite phase through out the treatment of the steel explaining the continuous rise in hardness. Plates 5, 6 and 7 give a clear picture of this. The carbides were small and sparingly distributed in the austenite phase after the first hour. After the second hour the carbides have spread all over the austenite phase and they are fine. By the third hour of holding the 
carbides have grown to bigger size but were still well spread in the matrix of the austenite. This trend also took place at $600^{\circ} \mathrm{C}$, but for $600^{\circ} \mathrm{C}$ treatment the carbide inclusions were not as dispersed at the second hour as in the $700^{\circ} \mathrm{C}$ treatment. It should be noted that the carbide grew after the second hour in both cases; the size of the carbide must have exceeded the optimum size that can effectively cause further increase in hardness as the carbide formed at $700^{\circ} \mathrm{c}$ after two hours of ageing [4] .

Ageing at $700^{\circ} \mathrm{C}$ for two hours gives us the optimum hardness in the experiment. This shows that the carbide inclusion can be used to strengthen Austenitic Manganese Steel if not allowed to exceed the optimum size that can impede dislocation movement and also not allowed to diffuse into the grain boundaries which might lead to embrittlement.

Since the precipitated carbide has led to an increase hardness of the steel, and from the relation between wear resistance and hardness we can say the precipitation strengthening can be used in improving the wear resistance of Austenitic Manganese Steel for service condition where abrasive loading is more than impact loading.

\section{CONCLUSSION AND RECOMMENDATION}

\subsection{Conclusion}

It has been established that Precipitation Strengthening (ageing) Mechanism can be used to improve the hardness and invariably the wear rate of the Hadfield Steel. The micrographs show that the treatment was able to cause precipitates in the matrix of the austenite phase and the hardness results show that the precipitates were able to increase the hardness of Austenitic Manganese Steel and that the ageing at $700^{\circ} \mathrm{C}$ for 2 hours gave the best result.

\subsection{Recommendation}

Further research to check the effect of varying carbide former on the ageing temperature and time is highly recommended. It is also recommended that the actual wear rate be determined and compared with that of the steel as water quenched under the same condition of abrasive wear.

\section{REFERENCES}

[1] Aver, H. S., 1981, “Austenitic Manganese Steel: Metal Handbook”, $8^{\text {th }}$ Edition

[2] Higgins, R. A., 1993, "Engineering Metallurgy Part 1: Applied Physical Metallurgy”, $6^{\text {th }}$ Edition, ELBS, Cornwall, Page (s): 50-56, 190-215 and 230-235.

[3] Katella, R., 1994,”Austenitic Wear Resistant Steel and Method For Heat Treatment”, Patent Paper. 
[4] Peter, N. W., 2004, "Hadfield's Manganese Steel and its Performance under Increased Wheel Loads", Presentation to the $83^{\text {rd }}$ Transportation research Board Annual Meeting, Washington, DC, Page 33

[5] Vander-Voort, G. F., 1996 “Applied Metallographic”, VNB, New York. Page 20. 